\title{
Author's reply to the letter to the editor regarding "Hemoglobin level is a more predictive diagnostic marker for acute pyelonephritis than mean platelet volume"
}

\author{
Mehmet Tekin $^{1} \cdot$ Mehmet Turgut $^{1}$
}

Received: 31 March 2016/Accepted: 11 April 2016/Published online: 26 April 2016

(C) Japanese Society of Nephrology 2016

Keywords Acute pyelonephritis · Children ·

Hemoglobin · Mean platelet volume

\section{To the Editor}

In contrast to our study, Jung and Lee reported that mean platelet volume (MPV) is not a predictive factor for acute pyelonephritis (APN), and hemoglobin level is a more predictive diagnostic marker for acute APN than MPV [1]. In their study, the hemoglobin levels of APN group were lower than the control group. In our study, the mean levels of hemoglobin were $12.30 \pm 1.12 \mathrm{~g} / \mathrm{dL}$ in the APN group, and $12.19 \pm 1.39 \mathrm{~g} / \mathrm{dL}$ in the lower urinary tract infection group. There was no statistically significant difference between the two groups in terms of hemoglobin levels ( $p=0.693$ ). It is thought that the differences between Jung and Lee's study and ours resulted from the fact that our study included non-anemic patients. In previous studies, it has been reported that low hemoglobin levels could be associated with decreased or increased platelet counts [24]. In addition, it was reported that MPV is inversely correlated with thrombocyte count [5]. Based on these observations, patients with anemia were excluded from the study; because, the low hemoglobin levels could alter the MPV values.

\section{Compliance with ethical standards}

Conflict of interest The authors declare that there are no conflicts of interest.

\section{References}

1. Jung SJ, Lee JH. Hemoglobin level is a more predictive diagnostic marker for acute pyelonephritis than mean platelet volume. Clin Exp Nephrol. 2016 (Epub ahead of print).

2. Cunha V, Ferreira M, Barosa R, Fonseca AG, Delerue F, Carvalho C. Iron-induced thrombocytopenia in severe iron-deficiency anemia. Expert Rev Hematol. 2015;8:247-51.

3. Subramaniam N, Mundkur S, Kini P, Bhaskaranand N, Aroor S. Clinicohematological study of thrombocytosis in children. ISRN Hematol. 2014;2014:389257.

4. Toprak SK, Tek I, Karakuş S, Gök N, Kurşun N. Does reactive thrombocytosis observed in iron deficiency anemia affect plasma viscosity? Turk J Haematol. 2012;29:248-53.

5. Bath PM, Butterworth RJ. Platelet size: measurement, physiology and vascular disease. Blood Coagul Fibrinolysis. 1996;7:157-61.
This reply refers to the article available at doi:10.1007/s10157-0161246-z.

\section{Mehmet Tekin}

drmehmettekin@hotmail.com

1 Department of Pediatrics, Adiyaman University, School of Medicine, Kahta Street, 02000 Adiyaman, Turkey 